\title{
PULMONARY STENOSIS WITH ATRIAL FIBRILLATION
}

\author{
BY \\ MAX ZOOB \\ From the Regional Thoracic Unit, Brook General Hospital, London S.E.18
}

In pulmonary stenosis with normal aortic root, sinus rhythm is the rule and atrial fibrillation appears to be rare (Abrahams and Wood, 1951; Campbell, 1954; Donzelot and D'Allaines, 1954; Kjellberg et al., 1955). The following case is considered to be of interest because the presence of this arrhythmia resulted in a clinical picture differing in several respects from that of pulmonary stenosis with sinus rhythm.

\section{Case Report}

The patient was a married man, aged 38, who weighed $126 \mathrm{lb}$. $(57 \cdot 2 \mathrm{~kg}$.) and was $5 \mathrm{ft} .6 \mathrm{in} .(165 \mathrm{~cm}$.) in height. A heart murmur had been discovered at the age of 1 year, and he had spent many years of his childhood in hospital. In adult life, however, he had been relatively free of symptoms. He could walk indefinitely on the level, and was able to lift 100 to $200 \mathrm{lb}$. (91-272 kg.) weights in the course of his occupation as a lorry driver. There was no syncope or anginal pain. In December 1961, he became more breathless on effort than usual and developed ankle œdema. This however responded to treatment with digitalis and diuretics, and he remained at work. When first seen in February 1962, he had atrial fibrillation with a ventricular rate of 80 a minute. The venous pressure was raised $8 \mathrm{~cm}$. above the sternal angle and a large amplitude systolic wave suggested tricuspid incompetence. This was confirmed by the presence of a pan-systolic murmur, with inspiratory accentuation near the xiphisternum: in some cycles it was accompanied by a short low-pitched diastolic murmur (Fig. 1A). The systolic murmur was pan-systolic in all areas (Fig. 1B) and no ejection systolic murmur could be identified. The cardiac impulse was diffuse and there was only slight parasternal pulsation suggesting right heart enlargement. The liver was considerably enlarged and the spleen was felt 2 inches below the costal margin. There was no œdema or ascites. The cardiogram showed low voltage and right bundle-branch block. The $T$ waves were sharply inverted in leads V 1-5 without S-T depression. Radioscopy showed remarkable enlargement of the right side of the heart (Fig. 2) and very small amplitude pulsations of all parts; the lung fields were clear and there was no effusion. The patient declined further investigation and returned to work. He was admitted six months later with severe œdema and breathlessness. The physical signs were unchanged apart from the addition of gross ascites. He died suddenly two days after admission.

Diagnosis. The differential diagnosis appeared to rest between Ebstein's anomaly of the tricuspid valve and pulmonary stenosis with normal aortic root. The enormous enlargement of the heart with poor pulsation, splitting of the heart sounds, pan-systolic murmur with variable early diastolic murmur, and right bundle-branch block, were all in keeping with the diagnosis of Ebstein's syndrome which appeared the likeliest explanation of the clinical picture.

Necropsy. The pericardium contained one litre of straw-coloured fluid. The heart, stripped of the great vessels, was greatly enlarged and weighed $742 \mathrm{~g}$. There was enormous dilatation of the right atrium, the walls of which showed pronounced trabeculation. The tricuspid valve was dilated, the diameter measuring $5 \mathrm{~cm}$., but it was otherwise normal (Fig. 3A). The muscle of the right ventricle was hypertrophied especially in the infundibulum where it reached a maximum thickness of $1.2 \mathrm{~cm}$. The pulmonary valve was represented by a diaphragm with a central orifice $0.5 \mathrm{~cm}$. in diameter (Fig. 3B). The left atrium and ventricle were normal but there was some dilatation of the mitral valve which measured $4 \mathrm{~cm}$. at its widest part. The coronary vessels were normal. 


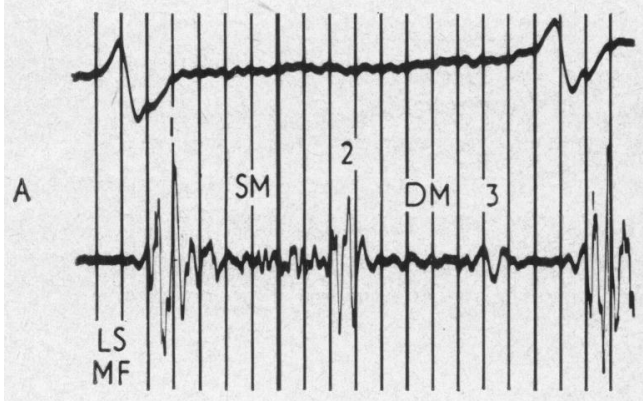

B

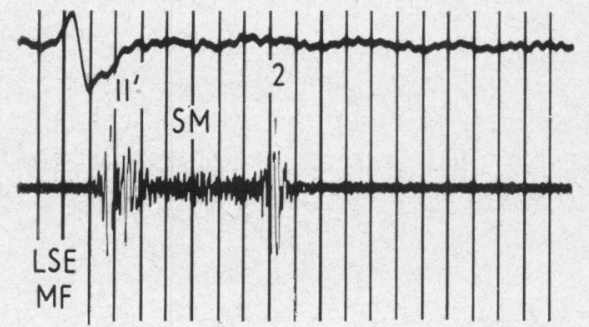

FIG. 1.-A. Phonocardiogram from the lower end of the sternum showing a systolic murmur (SM), low amplitude diastolic murmur (DM), and third sound (3). B. From the left sternal edge showing a pan-systolic murmur.

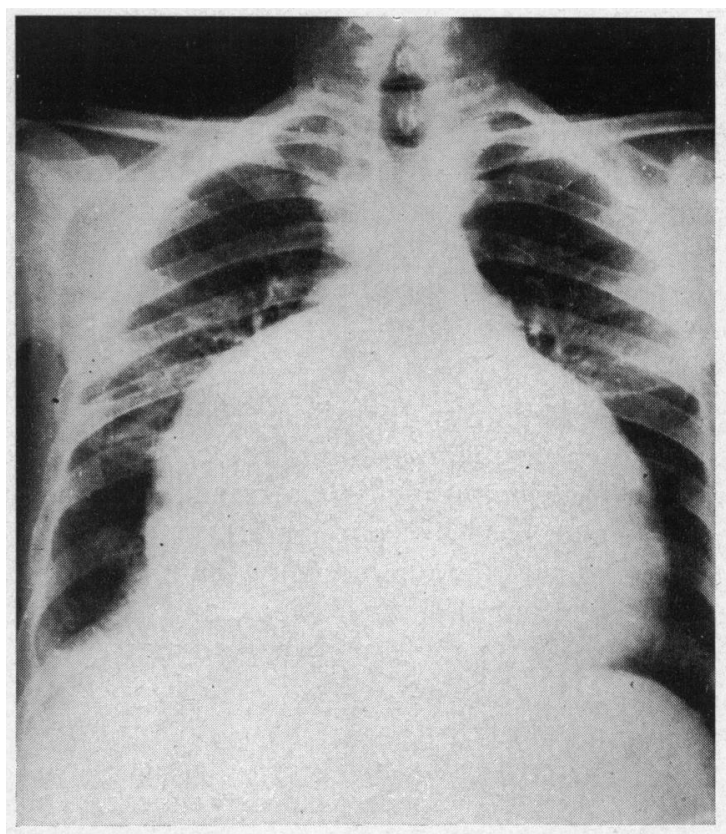

Fig. 2.-Skiagram showing enormous enlargement of the right side of the heart.

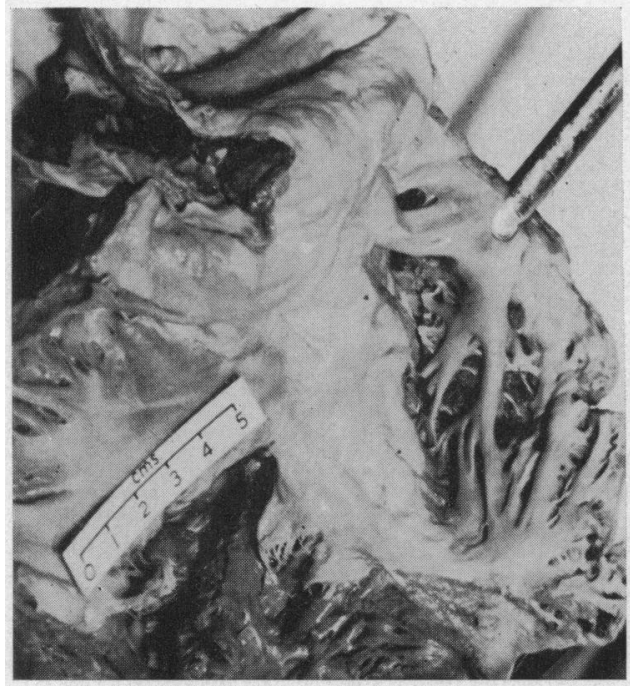

A

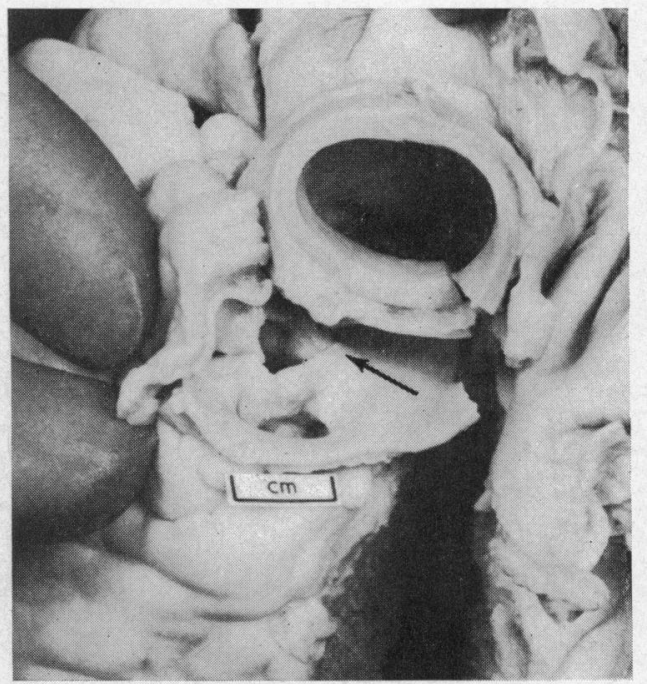

B

FIG. 3.-A. Necropsy specimen showing the hypertrophied and trabeculated right atrium (held in forceps), and dilated tricuspid valve ring. B. The aorta and pulmonary valve are viewed from above. The arrow points to the pulmonary valve cusps which are fused and thickened. The diameter of the central orifice measures $0.5 \mathrm{~cm}$ 


\section{Comment}

It is probable that the unusual clinical features of this case, particularly the enormous enlargement of the right atrium, were due to atrial fibrillation. In pulmonary stenosis, the greatly hypertrophied right ventricle appears to offer considerable resistance to filling; when there is sinus rhythm this is largely overcome by extremely powerful atrial contractions that may produce "a" waves of $10-15 \mathrm{~mm}$. $\mathrm{Hg}$, and a mean diastolic pressure of 7-10 mm. $\mathrm{Hg}$. In order to ensure comparable filling when atrial contractions are absent a similar pressure must be passively maintained throughout diastole. Such pressure acting as a distending force on the atrium and present over a long period of time could explain its great dilatation with consequent tricuspid incompetence.

\section{Conclusion}

When pulmonary stenosis is complicated by atrial fibrillation, the right atrial pressure must remain high throughout diastole to ensure filling of the hypertrophied right ventricle. This causes great enlargement of the right atrium, stretching of the tricuspid valve ring and consequent tricuspid incompetence. The ejection murmur of pulmonary stenosis is quiet owing to the low cardiac output and may be obscured by the murmurs of tricuspid incompetence. Splitting of the heart sounds, right bundle-branch block, and a huge still heart shadow on radioscopy, complete a clinical picture closely resembling Ebstein's syndrome.

\section{References}

Abrahams, D. G., and Wood, P. (1951). Pulmonary stenosis with normal aortic root. Brit. Heart J., $13,519$.

Campbell, M. (1954). Simple pulmonary stenosis. Pulmonary valvular stenosis with a closed ventricular septum. Brit. Heart J., 16, 273.

Donzelot, E., and D'Allaines, F. (1954). Traité des Cardiopathies Congénitales. Masson, Paris.

Kjellberg, S. R., Mannheimer, E., Rudhe, N., and Jonsson, B. (1955). Diagnosis of Congenital Heart Disease. Year Book Publishers, Chicago. 